\title{
Respon Kesuburan dan Hasil Tangkapan Ikan Terhadap Variablitias ENSO dan IOD di Perairan Teluk Lampung Indonesia
}

\author{
Kunarso $^{1 *)}$, Muhammad Yafi Arfad ${ }^{1}$, Heryoso Setiyono ${ }^{1}$, Azis Rifai ${ }^{1}$ dan Petrus Subardjo $^{1}$ \\ ${ }^{1}$ Departemen Oseanografi, Fakultas Perikanan dan Ilmu Kelautan, Universitas Diponegoro Jl. Prof. \\ Soedarto, SH Tembalang Tlp./Fax. (021) 7474698 Semarang 50275 \\ *Email : kunarsojpr@yahoo.com
}

\begin{abstract}
Abstrak
Perubahan suhu permukaan laut (SPL) dan klorofil-a dipengaruhi variabilitas iklim yang ada, variabilitas iklim yang dimaksud adalah ENSO (El Nino Southern Oscilation) dan IOD (Indian Oscillation Dipole). Studi tentang pengaruh ENSO dan IOD telah banyak dilakukan sebelumnya di Perairan Indonesia, namun belum ada studi terkait untuk wilayah Perairan Teluk Lampung. Tujuan dilakukannya penelitian ini untuk mengetahui respon perubahan SPL, klorofil-a, dan hasil perikanan pengaruh dari variabilitas iklim antar tahunan ENSO dan IOD di Perairan Teluk Lampung. Metode pendekatan masalah yng digunakan adalah metode deskriptif. Penelitian ini menggunakan data near real-time klorofil-a dan SPL dari satelit penginderaan jauh MODIS, indeks ENSO dan IOD, serta dilengkapi dengan data angin dari ECMWF. Data-data tersebut diolah dalam bentuk grafis dan diagram Hovmoller, selanjutnya dianalisis dengan statistik korelasi. Hasil penelitian menunjukan adanya respon nyata perubahan SPL dan klorofil-a terhadap adanya variabilitas iklim ENSO dan IOD. Respon yang fenomenal yaitu adanya suhu yang sangat rendah dan klorofil-a yang sangat tinggi pada saat fase La Nina - IOD (+), respon klorofil-a tinggi juga terjadi pada saat El Nino-IOD (+) namun tidak setinggi ketika La Nina-IOD(+). Respon SPL yang hangat dan klorofil-a rendah yag terjadi pada fase La Nina - IOD (-). Hal ini mengindikasikan bahwa kesuburan Perairan Teluk Lampung tertinggi terjadi pada saat La Nina - IOD (+), sebaliknya kesuburan perairan terendah terjadi pada saat La Nina - IOD (-). Pada saat kesuburan meningkat hasil perikanan juga meningkat dan pada saat kesuburan turun pada kondisi La Nina IOD(-) maka hasil tangkapan ikan juga menunjukkan penurunan.
\end{abstract}

Kata Kunci: Klorofil-a, SPL, ENSO, IOD, Perairan Teluk Lampung

\section{Abstract}

Sea Surface Temperature (SST) and chlorophyll-a variation are influenced by climate variability, i.e. ENSO (El Nino Southern Oscilation) and IOD (Indian Oscillation Dipole). Studies on the influence of ENSO and IOD have been conducted in several research in Indonesian Waters, yet there is a lack on the related studies for the Lampung Bay Waters region. This papers aim to determine the response of SPL and chlorophyll-a variation along with the capture fishery production towards the inter-annual climate variability of ENSO and IOD in the Lampung Bay. Using descriptive method, the study applied near real-time chlorophyll-a and SST data from MODIS, ENSO and IOD index, and ECMWF wind data. The data were processed through Hovmoller graphics and statistics correlation analysis. The results indicate an obvious response of SST and chlorophyll-a variation with climate variability of ENSO and IOD. Significant response was presented by a very low temperature and very high chlorophyll-a during the La Nina phase - IOD (+), a high chlorophyll-a response also occurs during El Nino-IOD (+) but not as high as when La Nina-IOD (+). Warm SST response and low chlorophyll-a occur in the La Nina phase - IOD (-). Therefore, the highest Lampung Bay productivity occur at La Nina - IOD (+), otherwise, the lowest productivity occurred at La Nina - IOD (-). Furthermore, the increasing of fertility has correlation with fisheries productivity escalation and vice versa.

Keyword: Chlorophyl-a, SST, ENSO, IOD, Lampung Bay Waters

\section{PENDAHULUAN}

Perubahan suhu dan klorofil-a di laut dipengaruhi variabilitas iklim yang ada, variabilitas iklim yang dimaksud adalah ENSO dan IOD (Susanto et al., 2001, Kunarso et al., 2019). ENSO dan IOD merupakan variabilitas iklim global yang dapat mempengaruhi kondisi oseanografi. Variabilitas iklim ENSO memiliki tiga fenomena yaitu kejadian normal, El Nino dan La Nina. Fenomena El Nino adalah peristiwa peningkatan Suhu Permukaan Laut (SPL) dari suhu normalnya di Pasifik Ekuator Timur. Sedangkan La Nina adalah fenomena SPL di wilayah Ekuator Samudera Pasifik mengalami penurunan dari suhu normalnya. Selain fenomena ENSO, 
terdapat fenomena lain yakni IOD yang merupakan interkasi antara variabilitas iklim global di Samudera Hindia (Panjaitan, 2011). Fenomena IOD menyebabkan terjadinya variabilitas antar tahunan di Perairan Samudera Hindia timur yang meliputi Perairan Indonesia (Kunarso et al., 2011). Saat fenomena IOD positif (+) mengakibatkan penurunan SPL dan fenomena IOD negatif (-) mengakibatkan kenaikan SPL karena adanya interaksi antara atmosfer dan laut (Kemili dan Putri, 2012).

Kandungan klorofil-a telah banyak digunakan sebagai indikator kesuburan atau produktivitas primer diantaranya yang digunakan dalam Marlian, (2015) dan Kunarrso et al (2018). Menurut Lehodey et al (2006), suhu permukaan laut dapat digunakan sebagai indikator pendugaan lokasi upwelling, downwelling, front yang terkait dengan kesuburan perairan. Informasi kesuburan perairan adalah hal yang penting untuk diketahui masyarakat pesisir. Belum adanya studi tentang pengaruh iklim terhadap kesuburan perairan Teluk Lampung mengakibatkan informasi kondisi dan karakteristik kesuburan perairan Teluk Lampung belum tersedia. Informasi pengaruh iklim terhadap kesuburan perairan dalam hal ini klorofil-a dan suhu permukaan laut sangatlah penting karena dengan dua parameter tersebut dapat diketahui tingkat kesuburan perairan yang ada, yang selanjutnya dapat digunakan sebagai dasar peramalan untuk mengetahui kesuburan perairan pada bulanbulan berikutnya berdasarkan data iklim yang ada. Berbagai macam parameter mempengaruhi kesuburan, salah satunya adalah variabilitas iklim seperti Indian Oscillation Dipole Mode (IOD) dan El Nino Southern Oscilation (ENSO) (Kunarso et al, 2011)

Tujuan dilakukannya penelitian ini adalah untuk mengkaji pengaruh variabilitas iklim ENSO dan IOD terhadap variasi suhu permukaan laut, klorofil-a (kesuburan) dan produksi perikanan di Perairan Teluk Lampung. Lokasi penelitian di Teluk Lampung Kabupaten Pesawaran (Gambar 1)

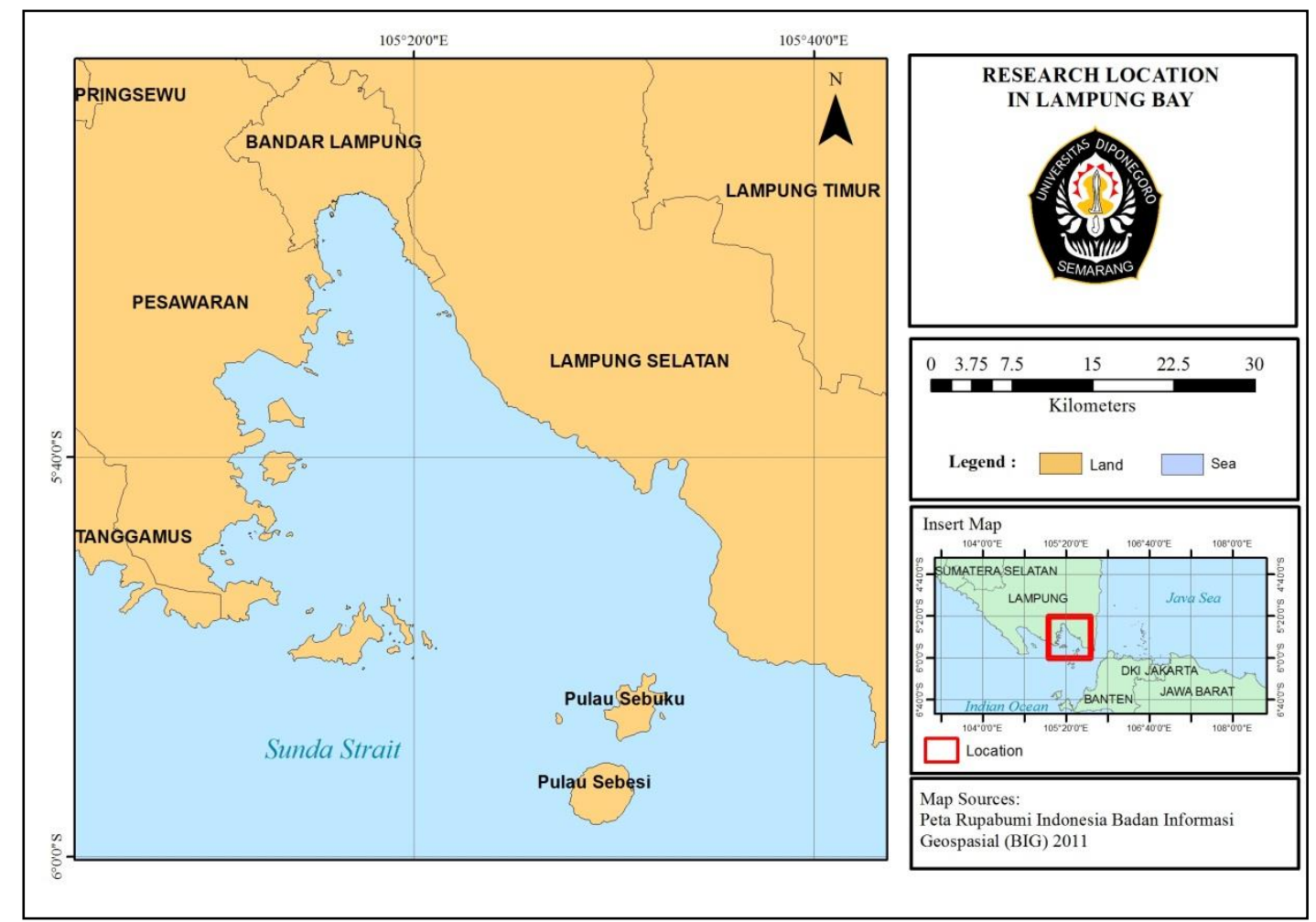

Gambar 1. Lokasi Penelitian

\section{MATERI DAN METODE \\ Materi Penelitian}

Materi yang digunakan dalam penelitian ini berupa data near real-time selama 10 tahun dari tahun 2007 hingga 2017 yang terdiri dari data utama dan data pendukung. Data utama terdiri dari data suhu permukaan laut (SPL), data klorofil-a, indeks variabilitas iklim ENSO dan IOD. Data pendukung yang digunakan adalah data angin. Data SPL dan klorofil-a didapat dari pendekatan citra satelit Aqua MODIS. Indeks variabilitas iklim ENSO menggunakan nilai anomali suhu permukaan laut (SPL) di NINO3,4. Indeks variabilitas iklim IOD menggunakan nilai Dipole Mode Index (DMI). Sedangkan data pendukung yang digunakan adalah data arus laut yang didapat dari My Ocean dan data angin didapat dari European Centre for Medium-Range Weather Forecasts (ECMWF). Data perikanan yang berupa data CPUE time series bulanan tahun 2014-2016 diperoleh dari Satuan Pengawasan Sumber Daya Kelautan dan Perikanan Kabupaten Pesawaran, Lampung

\section{Metode Penelitian}


Metode yang digunakan dalam penelitian ini adalah metode kuantitatif, dengan data penelitian berupa angka-angka dan analisis menggunakan statistik (Sugiyono, 2009). Pengumpulan data secara kuantitatif meliputi data SPL, data klorofil-a, indeks variabilitas iklim ENSO dan IOD, dan data angin. Data yang dihasilkan berupa angka-angka yang kemudian diolah sehingga diperoleh gambaran variabilitas klorofil-a dan SPL secara spasial dan temporal yang akan dikaitkan dengan pengaruh dari variabilitas iklim ENSO dan IOD yang selanjutnya dikaitkan dengan hasil produksi perikanan.

\section{Metode Pengumpulan Data}

Data SPL dan klorofil-a yang digunakan dalam penelitian berupa citra satelit dengan format data Net Common Data File (NetCdf). Data citra satelit SPL dan klorofil-a tersebut berupa data bulanan (monthly) level 3 dengan resolusi spasial 4 km selama 10 tahun dari bulan Januari 2007 hingga Desember 2017 dengan total 120 citra SPL dan 120 citra klorofil-a.

Data variabilitas iklim ENSO dan IOD merupakan nilai indeks anomali SPL di NINO3,4 dan Dipole Mode Index (DMI) selama 10 tahun. Anomali SPL di NINO3,4 merupakan perbedaan anomali SPL di Samudra Pasifik Timur yang berupa data bulanan. Data DMI merupakan anomali SPL di Samudera Hindia Barat dan Samudera Hindia Timur.

Data angin yang digunakan merupakan hasil pemodelan masing-masing dari instansi European Centre for Medium-Range Weather Forecasts (ECMWF) dan My Ocean. Data angin memiliki resolusi spasial sebesar 13,8 $\mathrm{km}$. Data salinitas diperoleh dari situs dengan resolusi spasial sebesar kurang lebih $1^{\circ}$.

Data perikanan yang berupa data CPUE time series bulanan tahun 2014-2016 diperoleh dari Satuan Pengawasan Sumber Daya Kelautan dan Perikanan Kabupaten Pesawaran, Lampung.

\section{Metode Pengolahan dan Analisis Data}

Papengolahan data, tahap awal yang dilakukan adalah klasifikasi data. Klasifikasi awal yang dilakukan adalah interpretasi citra., data SPL, klorofil-a salinitas, dan angin tersebut dilakukan pengelompokan untuk melihat pola distribusi spasial SPL, klorofil-a, salinitas dan angin. Untuk mengidentifikasi kejadian/fenomena dari variabilitas iklim dianalisis berdasarkan indeks dari masing-masing variabilitas iklim ENSO dan IOD

Citra serta data yang diperoleh kemudian dengan menggunakan perangkat yang ada baik perangkat keras maupun perangkat lunak akan menghasilkan beberapa hasil seperti grafik untuk yang berasal dari data variatabilitas iklim sedangkan untuk klorofil, suhu dan angin akan menghasilkan peta pola sebaran secara temporal. Pada tahap selanjutnya data-data yang sudah diolah tersebut dilakukan analisis untuk mengetahui keterkaitan antara data citra yang sudah diolah dengan data variabilitas iklim (ENSO dan IOD) dan data produksi perikanan.

\section{HASIL DAN PEMBAHASAN}

Variasi Antar Tahunan SPL dan Klorofil-a

Variasi antar tahunan SPL dan klorofil-a selama 10 tahun dari tahun 2007 hingga 2017 di Perairan Teluk Lampung ditampilkan dalam bentuk grafik dalam Gambar 2.

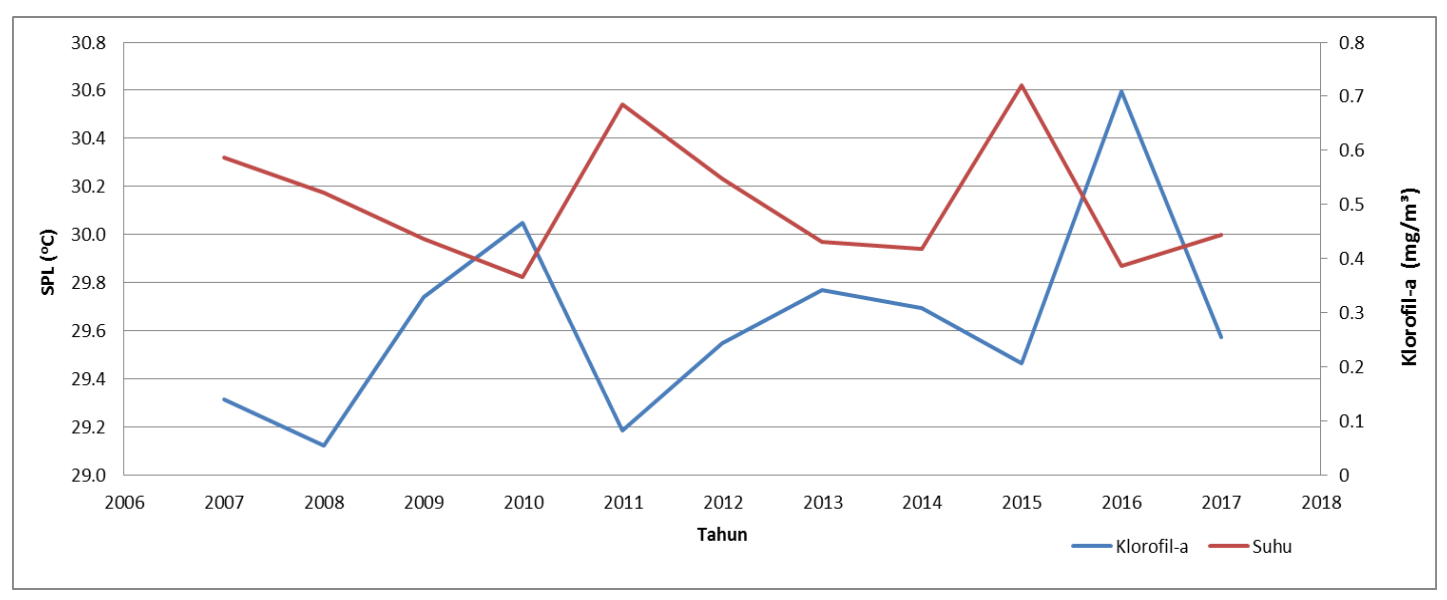

Gambar 2. Variasi antar tahunan SPL dan Klorofil-a tahun 2007-2017 


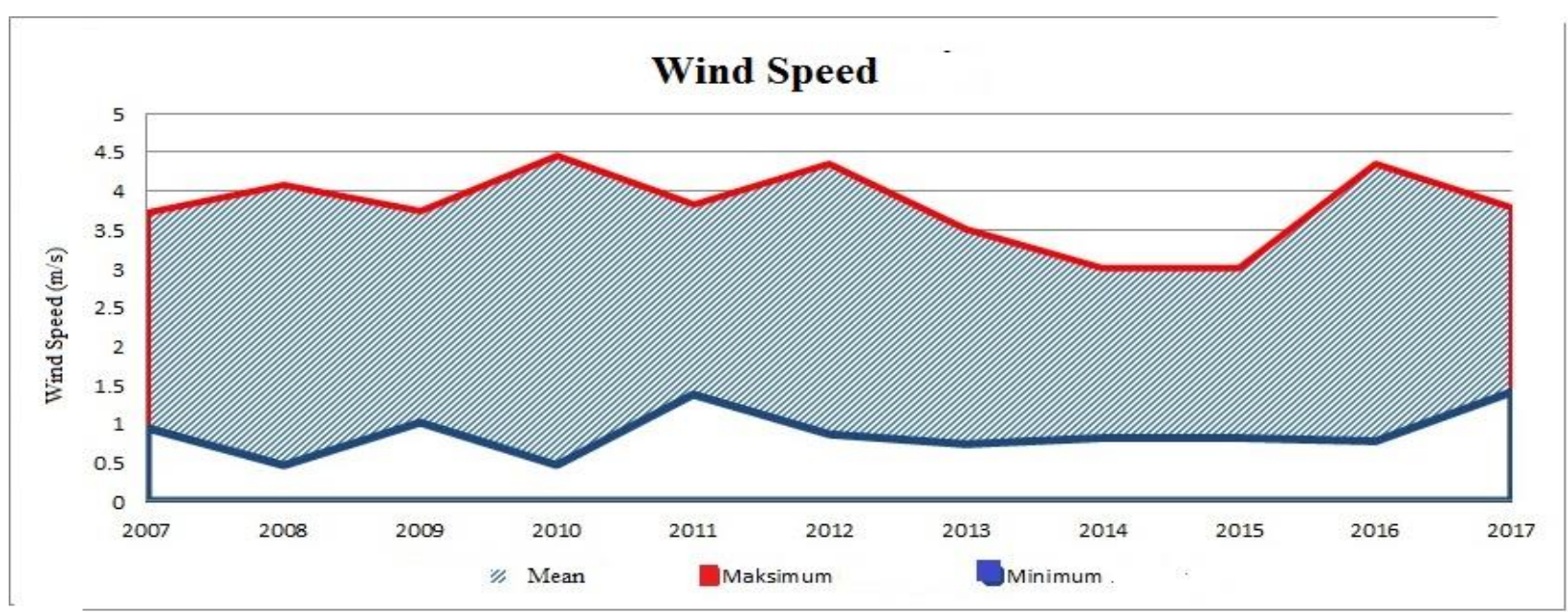

Gambar 3. Variasi antar tahunan kecepatan angin tahun 2007- 2017

Berdasarkan Gambar 2 tersebut menunjukan bahwa suhu mencapai nilai tertinggi pada tahun 2005 dan mencapai nilai terendah pada tahun 2010. Sedangkan untuk klorofil-a mencapai nilai tertinggi pada tahun 2016 dan mencapai nilai terendah pada tahun 2008. Variasi antar tahunan kecepatan angin pada Gambar 3 menunjukan bahwa angin mencapai kecepatan tertinggi pada tahun 2008 dan 2011 kemudian angin mencapai kecepatan terendah pada tahun 2016.

Nilai rata-rata SPL tertinggi sebesar $30,59{ }^{\circ} \mathrm{C}$ yang terjadi pada tahun 2016 dan nilai rata-rata terendah terjadi pada tahun 2008 dengan nilai sebesar $29,12{ }^{\circ} \mathrm{C}$. Berdasarkan pengolahan data diperoleh selama 10 tahun suhu terpanas yang terjadi di perairan Teluk Lampung terjadi pada tahun 2016 dengan suhu tertinggi sebesar $34,20{ }^{\circ} \mathrm{C}$ dan suhu terdingin sebesar $25,36{ }^{\circ} \mathrm{C}$ pada tahun 2011. Data klorofil-a menunjukan bahwa rata-rata klorofil-a tertinggi terjadi pada tahun 2015 dengan nilai klorofil-a sebesar $0,720 \mathrm{mg} / \mathrm{m}^{3}$ sedangkan klorofil-a rata-rata klorofil-a terendah terjadi pada tahun 2010 dengan nilai klorofil-a sebesar $0,365 \mathrm{mg} / \mathrm{m}^{3}$. Selain itu berdasarkan data selama 10 tahun terlihat bahwa nilai klorofil-a tertinggi terjadi pada tahun 2011 dengan nilai sebesar 6.054 $\mathrm{mg} / \mathrm{m}^{3}$ dan nilai klorofil-a terendah pada tahun 2014 dengan nilai sebesar $0,086 \mathrm{mg} / \mathrm{m}^{3}$. Nilai rata-rata angin tercepat terjadi pada tahun 2014 dengan nilai sebesar $2,487 \mathrm{~m} / \mathrm{s}$ dan nilai rata-rata angin terendah terjadi pada tahun 2016 dengan nilai sebesar 1,444 m/s. Berdasarkan data selama 10 tahun terlihat bahwa nilai kecepatan angin tertinggi sebesar 4,466 m/s yang terjadi pada tahun 2010 dan nilai kecepatan angin terendah sebesar 0,462 $\mathrm{m} / \mathrm{s}$ yang terjadi pada tahun 2008

Berdasarkan analisis variabilitas SPL dan klorofil-a di Perairan Teluk Lampung saling berbanding terbalik, hal ini berarti bahwa jika SPL terjadi peningkatan maka klorofil-a mengalami penurunan nilai dan berlaku sebaliknya. Hubungan terbalik tersebut terjadi hampir pada semua periode tahun yang dianalisis. Keterkaitan SPL dengan klorofil-a diungkapkan Saraswata (2013) bahwa suhu mempengaruhi fotosintesis fitoplankton di perairan secara langsung dan tidak langsung. Secara langsung suhu mempengaruhi reaksi enzimatik pada proses fotosintesis fitoplankton, dan secara tidak langsung suhu merubah struktur hidrologi kolom perairan yang mempengaruhi distribusi fitoplankton. Terkait dengan kecepatan angin yaitu berdasarkan analisis variabilitas SPL saling berbanding terbalik dengan kecepatan angin yang artinya ketika angin mencapai kecepatan maksimum maka SPL akan mengalami penurunan atau pendinginan. Hal tersebut terjadi karena ketika angin semakin menguat maka permukaan air semakin tidak tenang dan mengakibatkan kurangnya serapan panas di perairan (Rasyid, 2010; Kunarso et al.,2017).

\section{Variabilitas SPL dan Klorofil-a Pada Variasi ENSO dan IOD}

Pola variabilitas SPL terhadap ENSO dan IOD diamati melalui diagram hovmoller pada Gambar 4. , sedangkan Klorofil-a terhadap ENSO dan IOD dideskripsikan dalam diagram hov moller pada Gambar 5. 

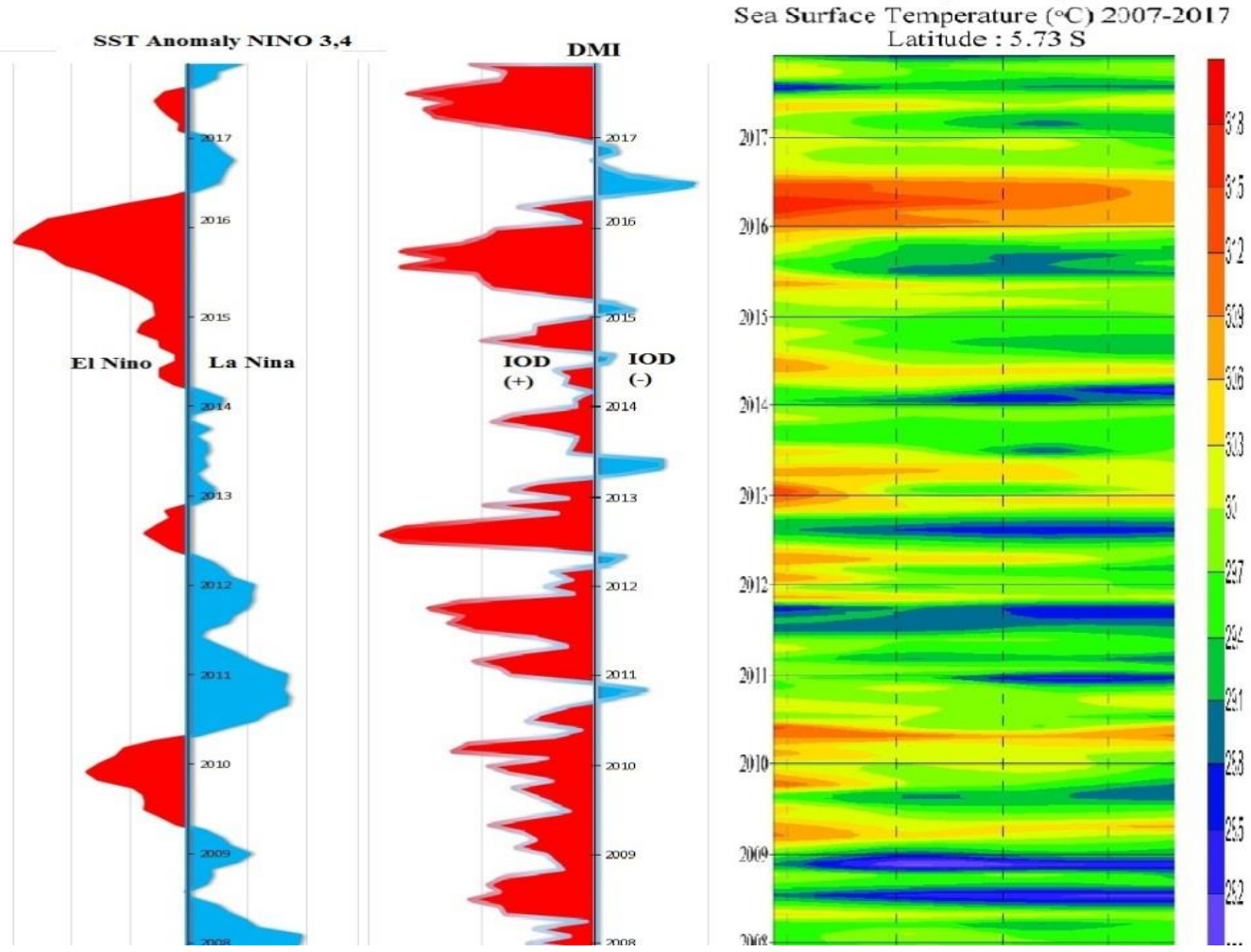

Gambar 4. Diagram Hovmoller variabilitas SPL pada variasi ENSO dan IOD
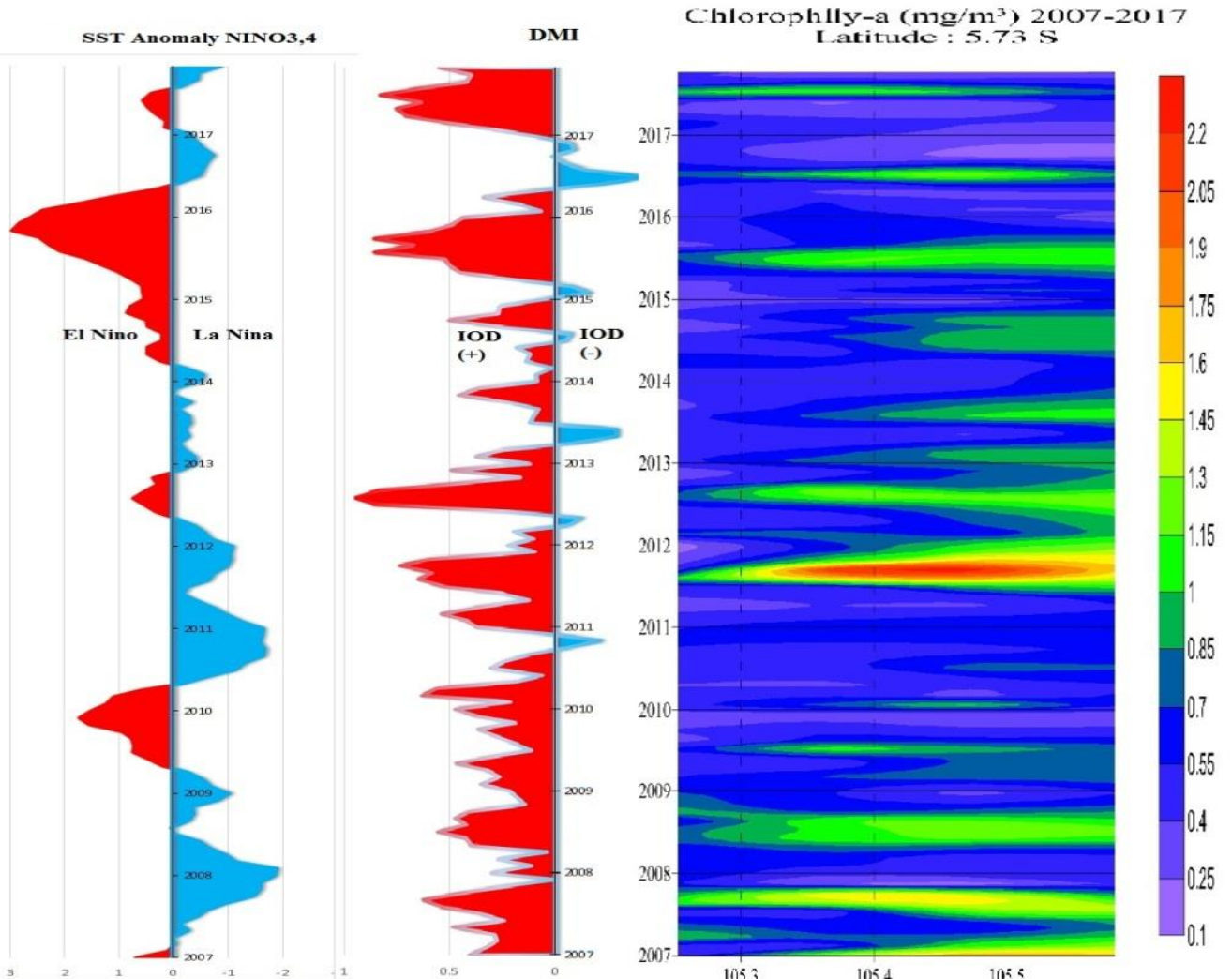

Gambar 5. Diagram Hovmoller variabilitas Klorofil-a pada variasi ENSO dan IOD

Diagram Hovmoller di atas menggambarkan pola umum dan keterkaitan variabilitas SPL pada variasi ENSO dan IOD. Interpretasi diagram Hovmoller dilakukan dengan mengambil beberapa periode yang mewakili fenomena variabilitas iklim El Nino, La Nina, IOD(+), IOD(-) dan Normal. 
Tingkat kesuburan di Perairan Teluk Lampung yang diidentifikasi dalam periode 10 tahun berdasarkan diagram Hovmoller klorofil-a disajikan dalam Tabel 1

Tabel 1. Variabilitas Kesuburan

\begin{tabular}{ccc}
\hline Kasus/Fase & Tahun & Tingkat Kesuburan \\
\hline La Nina - IOD (+) & 2007,2008 dan2011 & Tinggi \\
\hline La Nina - IOD (-) & 2010 dan 2016 & Rendah \\
\hline El Nino - IOD (+) & 2009 dan 2015 & Sedang \\
\hline Normal & 2013 & Sedang \\
\hline
\end{tabular}

Keterangan : Tingkat Kesuburan (TK)

Rendah : $0,1<\mathrm{TK}>0,85\left(\mathrm{mg} / \mathrm{m}^{3}\right)$

Sedang : $0,85<\mathrm{TK}>1,45\left(\mathrm{mg} / \mathrm{m}^{3}\right)$

Tinggi : $1,45<\mathrm{TK}\left(\mathrm{mg} / \mathrm{m}^{3}\right)$

Hasil analisis menunjukkan tingkat kesuburan tinggi terjadi pada fase La Nina - IOD (+) yang terjadi tahun 2007, 2008, dan 2011 dan kesuburan tertinggi terjadi pada tahun 2011, tingkat kesuburan sedang terjadi pada fase El Nino - IOD (+) yang terjadi tahun 2009 dan 2015 dan saat Normal tahun 2013. Tingkat kesuburan terendah terjadi pada fase La Nina - IOD (-) pada tahun 2010 dan 2016.

Pengaruh variabilitas iklim ENSO dan IOD terhadap variabilitas SPL dan klorofil-a di Perairan Teluk Lampung mempunyai keterkaitan yang berbeda-beda. Kondisi perairan dengan SPL yang sangat rendah dan klorofil-a yang sangat tinggi terjadi pada periode La Nina - IOD (+) terjadi pada tahun 2011, kondisi yang hampir sama juga terjadi pada tahun 2007 dan 2008 menunjukkan bahwa respon periaran Teluk Lampung mengalami kondisi tersubur pada periode La Nina -IOD (+). Hal ini sesuai dengan yang disebutkan Kunarso (2014) dalam Hafizhurrahman (2015) menjelaskan hal yang sama dimana ketika La Nina - IOD (+) tahun 2008 menyebabkan perairan Selatan Jawa dan Barat Sumatera mengalami peningkatan proses upwelling yang mengakibatkan suhu perairan dingin dan kadar klorofil-a meningkat. Kondisi diduga bisa terjadi karena adanya proses upwelling yang tinggi dipicu adanya IOD (+) dan juga diduga adanya curah hujan yang tinggi dipicu terjadinya La Nina sehingga run off sungai yang membawa nutrien dari daratan meningkat. Tingginya proses upwelling pada saat IOD (+) dipicu adnya peningkatan angin monsun yang menyebabkan upwelling di pantai timur Teluk Lampung pada saat musim timur hingga peralihan 2 (bulan Juni-Oktober), hal ini sesuai dengan hasil penelitian Kunarso et al., 2018. Secara tidak langsung angin yang disebabkan monsun yang meningkat kecepatannya karena pengaruh $\mathrm{IOD}(+)$ berdampak pada meningkatnya intensitas upwelling yang menyebabkan tingginya klorofil-a dan rendahnya SPL.

Fenomena lain yang ditemukan dari analisis yaitu di Perairan Teluk Lampung terjadi SPL tinggi dan klorofila yang rendah pada saat La Nina - IOD (-) tahun 2010 dan 2016. Hal ini terjadi karena penurunan intensitas upwelling karena melemahnya kecepatan angin monsun yang terjadi, hal ini menyebabkan suplai air dingin dari lapisan bawah dan juga suplai nutrien menurun yang berakibat SPL lebih hangat dan klorofil-a menurun.. Ketika La Nina - IOD (-) maka angin monsun yang bertiup di Indonesia melemah. Hal ini sesuai dengan hasil riset Kunaso (2014) yang menjelaskan pada saat La Nina - IOD (-) kecepatan angin monsun melemah. Melemahnya angin monsun menyebabkan proses upwelling yang terjadi di Selatan Jawa hingga Barat Sumatera melemah, hal ini menyebabkan suplai massa air dingin dan nutrien dari lapisan bawah juga menurun. Proses inilah yang mengakibatkan pada saat La Nina - IOD (-) di Perairan Teluk Lampung terjadi pelemahan upwelling, sehingga perairan menjadi lebih hangat dan kesuburan menurun yang tampak dari indikator klorofil-a yang konsentrasinya menurun.

\section{Respon Hasil Tangkapan Ikan Terhadap ENSO dan IOD}

Berdasarkan analisis dalam Gambar 5, menunjukkan ketika terjadi El-Nino IOD(+) tahun 2015 terjadi peningkatan kesuburan perairan yang tampak meningkatnya klorofil-a (Gambar 4). Peningkatan kesuburan yang tinggi ini ternyata diikuti meningkatnya hasil tangkapan dalam bentuk CPUE (Gambar 5). Peningkatan hasil tangkapan tampak hampir sefase dengan peningkatan indek ENSO. Kondisi sebaliknya ternjadi ketika pada tahun 2016 terjadi fenomena La Nina-IOD(-), tampak respon wilayah Teluk Lampung menunjukkan adanya penurunan kesuburan yang tampak dari penurunan klorofil-a tahun 2016 (Gambar 4), dan peningkatan SPL (Gambar 3). Adanya penurunan kesuburan wilayah tampak diikuti dengan penurunana hasil produksi perikanan, yang tampak dari penurunan CPUE tahun 2016 (Gambar 5). Produksi perikanan di Teluk Lampung pada tahun 2016 mengalami paceklik ikan. 


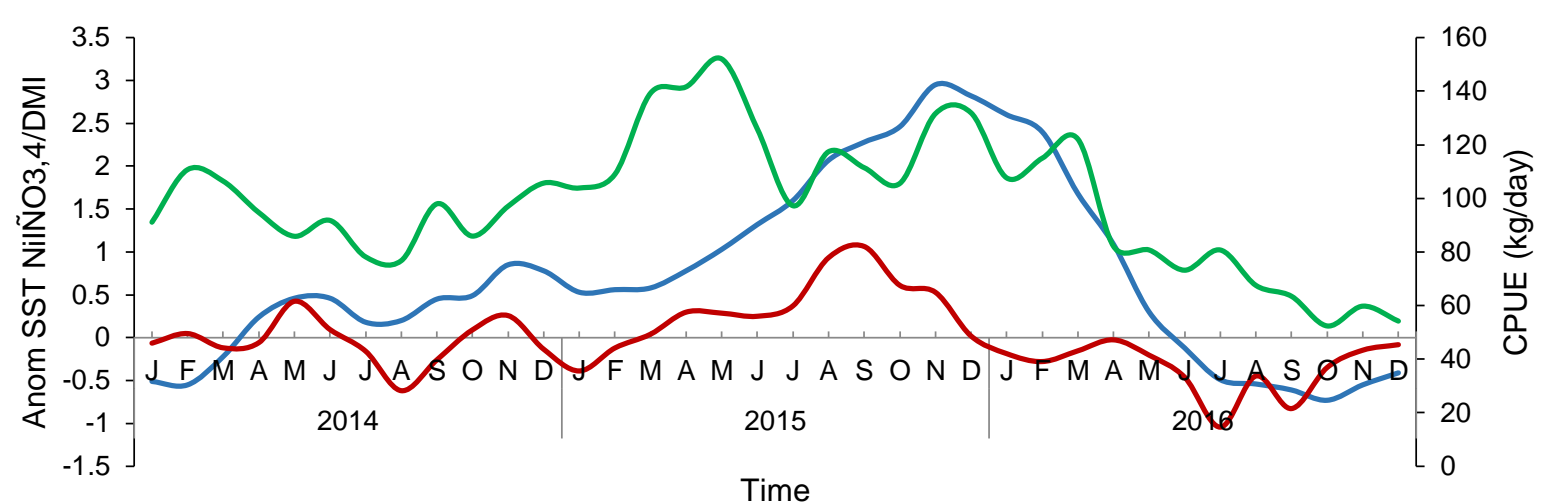

- ANOM SST NIÑO3.4 —DMI —CPUE Pesawaran

Gambar 5. Variabilitas Indek ENSO (Anom SST NIÑO3,4), indek IOD (Dipole Mode Index/DMI) dan hasil tangkapan ikan (Catch Per Unit Effort/CPUE) dari Teluk Lampung tahun 2014-2016

\section{KESIMPULAN}

Pengaruh ENSO dan IOD terhadap variabilitas SPL dan klorofil-a di Perairan Teluk Lampung memiliki dampak yang nyata pada periode-periode khusus. Terutama saat La Nina - IOD (+) menimbulkan SPL rendah dan kesuburan tinggi, kadar klorofil-a lebih dari $1,45 \mathrm{mg} / \mathrm{m}^{3}$. Kondisi sebaliknya terjadi ketika periode La Nina IOD (-) menimbulkan SPL hangat dan kesuburan rendah dengan kadar klorofil-a sebesar berkisar 0,1-0,85 $\mathrm{mg} / \mathrm{m}^{3}$. Hal ini mengindikasikan kesuburan Perairan Teluk Lampung tertinggi terjadi pada saat La Nina - IOD (+), sebaliknya kesuburan perairan terendah terjadi pada saat La Nina - IOD (-).

Variabilitas kesuburan sebagai respon variabilitas iklim,tampak mempengaruhi produktifitas perikanan, pada saat terjadi peningkatan kesuburan pada periode El Nino-IOD (+) diikuti dengan peningkatan produksi perikanan. Kondisi sebaliknya saat penurunan kesuburan perairan pada saat La Nina-IOD(-), produksi perikanan juga menurun (terjadi paceklik ikan)

\section{DAFTAR PUSTAKA}

Fadika, U; A. Rifai, ; dan B. Rochaddi,. 2014. Arah dan Kecepatan Angin Musiman Serta Kaitannya dengan Sebaran Suhu Permukaan Laut Di Selatan Pangandaran Jawa Barat. Jurnal Oseanografi, 3(3): 429 437

Hafizhurrahman, I; Kunarso; dan A.A.D.Suryoputro. 2015. Pengaruh IOD (Indian Ocean Dipole) Terhadap Variabilitas Nilai serta Distribusi Suhu Permukaan Laut dan Klorofil-a pada Periode Upwelling di Perairan sekitar Bukit Bandung Bali. Jurnal Oseanografi. 4(2):423-433

Kemili, P. dan M.R. Putri. 2012. Pengaruh Durasi dan Intensitas Upwelling Berdasarkan Anomali Suhu Permukaan Laut Terhadap Variabilitas Produktivitas Primer di Perairan Indonesia. Ilmu dan Teknologi Kelautan Tropis, 4(1):66-79.

Kunarso. 2014. Pengaruh Monsun, El Niño-Southern Oscillation dan Indian Ocean Dipole Terhadap Waktu dan Daerah Penangkapan Ikan Tuna di Samudra India Bagian Timur. [Disertasi], Institut Teknologi Bandung, Bandung

Kunarso., S. Hadi., N. S. Ningsih., M. S. Baskoro. 2011. Variabilitas Suhu dan Klorofil-a di Daerah Upwelling pada Variasi Kejadian ENSO dan IOD di Perairan Selatan Jawa sampai Timor. Ilmu Kelautan. 16(3):171180

Kunarso; M.Zainuri, ; R. Ario, ; B. Munandar, ; dan M. Prayogi, . 2017. Impact of Monsoon to Aquatic Productivity and Fish Landing at Pesawaran Regency Waters. 3rd International Conference on Tropical and Coastal Region Eco Development 2017. D.I Yogtakarta

Kunarso; M.Zainuri, ; R. Ario, ; B. Munandar, ; dan M. Prayogi. 2018. Impact of Monsoon to Aquatic Productivity and Fish Landing at Pesawaran Regency Waters. IOP Conf. Series: Earth and Environmental Science 116 (2018) 012021

Kunarso; A. Wirasatriya; Irwani; A. Satriyadi; M. Helmi; H. Prayogi; B Munandar. Impact of Climate Variability to Aquatic Productivity and Fisheries Resources in Jepara Water. IOP Conf. Series. Earth and Environmental

Science.

246

(2019)

012021 
Lehodey, P., I. Senina, and R. Murtugudde. 2006. A Spatial Ecosystem and Population Dynamics Model (SEAPODYM)-Modelling of Tuna and LikeTuna Populations. Progress in Oceanography. 78:304-318.

Marlian, N; A. Damar, ; dan H. Effendi, . 2015. Distribusi Horizontal Klorofil-a Fitoplankton Sebagai Indikator Tingkat Kesuburan Perairan di Teluk Meulaboh Aceh Barat. Jurnal Ilmu Pertanian Indonesia (JIPI), 20(3): 272 - 279.

Panjaitan, R.J.A. 2011. Variabilitas Konsentrasi Klorofil-a dan Suhu Permukaan Laut Dari Citra Satelit Aqua Modis Serta Hubungannya Dengan Hasil Tangkapan Ikan Lemuru di Perairan Selat Bali. [Skripsi]. Fakultas Perikanan dan Ilmu Kelautan Institut Pertanian Bogor, Bogor

Rasyid, J. A. 2010. Distribusi Suhu Permukaan pada Musim Peralihan Barat-Timur Terkait dengan Fishing Ground Ikan Pelagis Kecil di Perairan Spermonde. Torani (Jurnal Ilmu Kelautan dan Perikanan ), 20(1) : 1-7.

Saraswata, A. G., P. Subardjo, Muslim. 2013. Pengaruh Monsun Terhadap Distribusi Suhu Permukaan Laut Dan Klorofil-A di Perairan Selatan Bali. Jurnal Oseanografi, 2(1): 79 - 87

Sugiyono. 2009. Metode Penelitian Kuantitatif Kualitatif dan R\&D. Alfabeta, Bandung

Susanto, R, D; A.L. Gordon ; dan Q. Zheng . 2001. Upwelling along the Coast of Java and Sumatra and Its relation to ENSO, J. Geophysical Research Letters. 28(8): 1599-1602 